\title{
TMS Foundation Celebrates Those Who Make a Difference at TMS2019
}

\section{Kaitlin Calva}

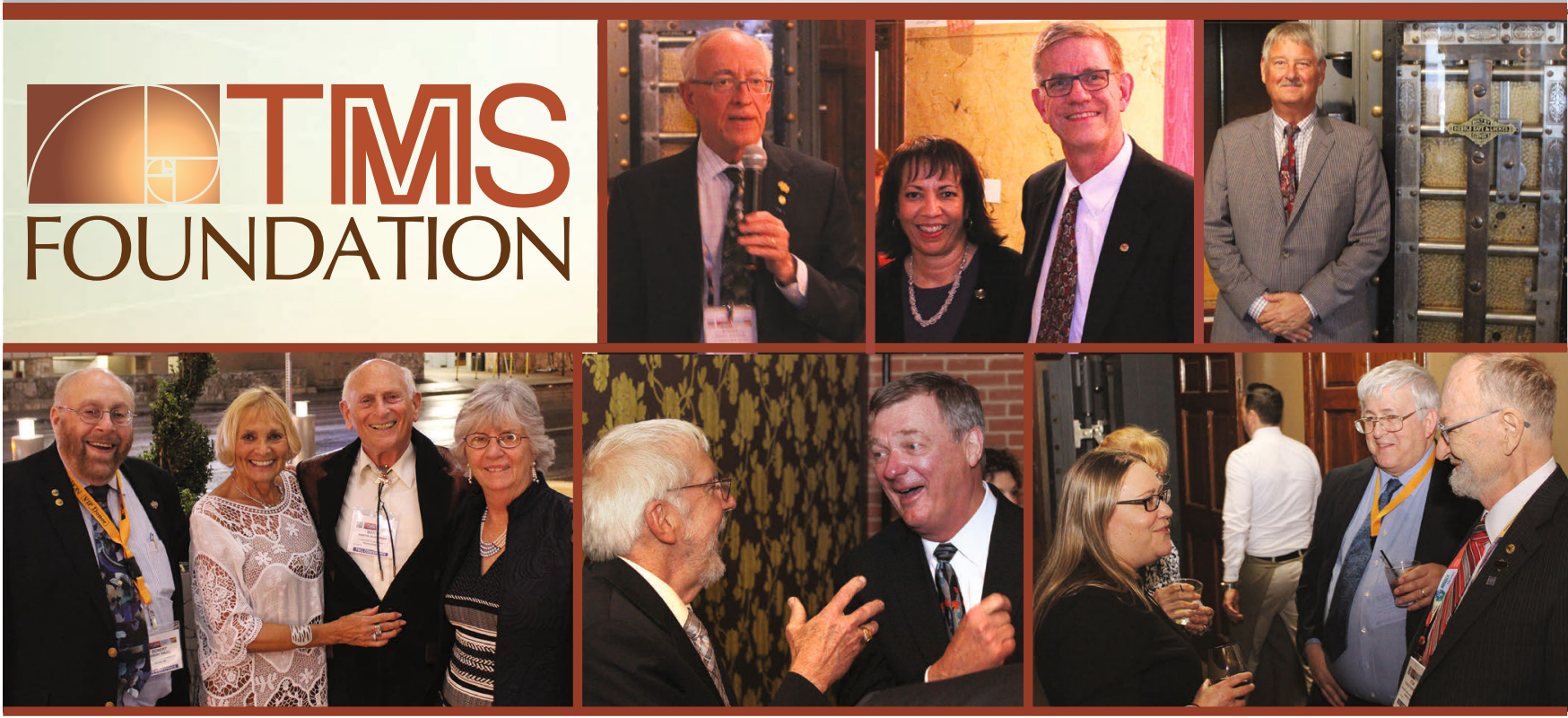

"You are people who care, who make a difference, who make an impact on young lives and careers," said Garry W. Warren, Chair, TMS Foundation Board of Trustees, as he welcomed attendees of the TMS Foundation Donor Appreciation Dinner held during the TMS 2019 Annual Meeting \& Exhibition. "You are the top donors who are building the future of the materials professions. Thank you from the TMS Foundation and from the lives you touch."

Warren thanked donors for their contributions and attendance at the evening's festivities, while also highlighting good news about the Foundation's progress over the past year, as 2018 marked the Foundation's 25th

\section{You Can Make a Difference, Too}

Those who give to the TMS Foundation are helping to not only provide financial support, but also meaningful experiences to TMS members in the most critical stages of their career development. Join your colleages in making a gift to the Foundation, and you could see your name on the 2019 Annual Giving Honor Roll or on the Lifetime Giving Honorific Societies lists. To contribute online, and to see all donation options, visit www.TMSFoundation.org. anniversary. It was a top year for donations, both during the year-end appeal and through a division scholarship fundraising campaign; the number of new donors increased over 2017; and a new endowed award was established through the TMS Foundation-the William D. Nix Award. (For more details on the Foundation's 2018

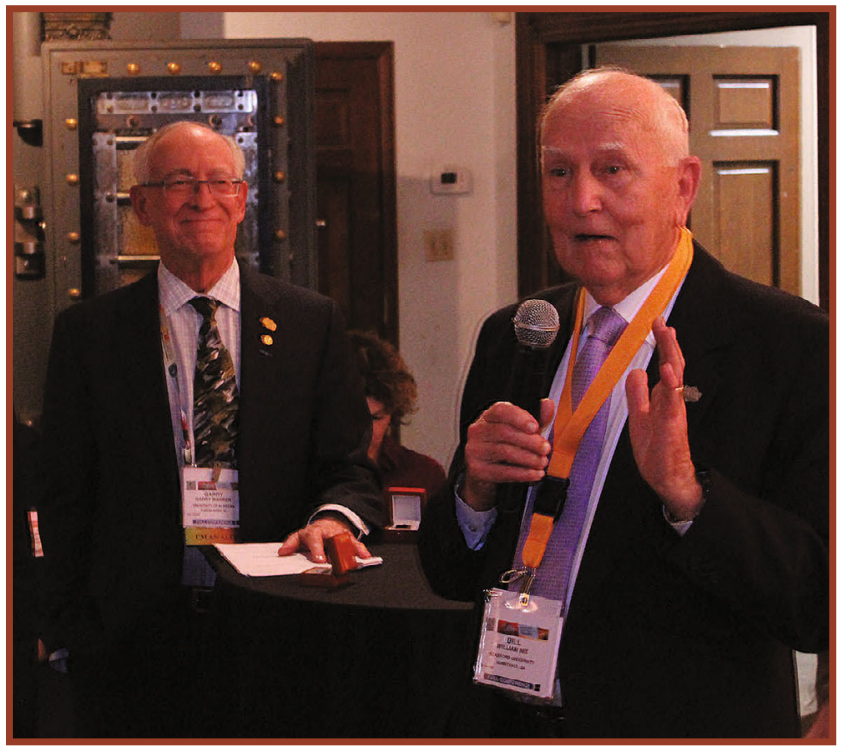

Bill Nix (right) took a moment to thank and highlight the accomplishments of his Ph.D. students, who fully funded and established the new William D. Nix Award in his honor through the TMS Foundation in 2018. 


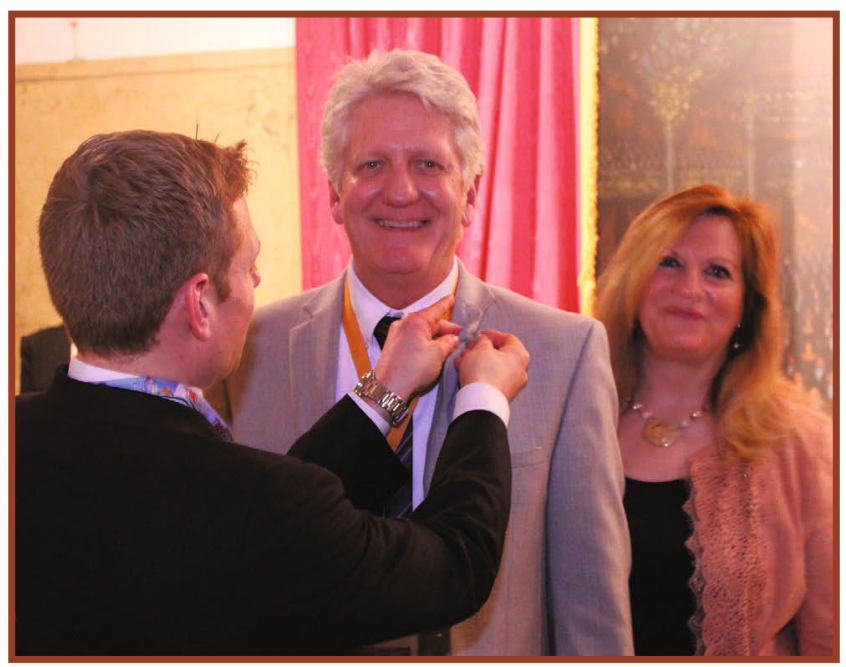

Michael and Cecilia Mills (center, right) receive their pin as new members of the Silver Society from Andrew Baker (left), recognizing lifetime giving to the Foundation of at least $\$ 5,000$ up to $\$ 10,000$.

activities, see the May 2019 JOM article, "The TMS Foundation: Success in 2018.")

"As donors, you share a common goal to support students and young professionals in the critical early years of their careers. Their contributions to research, academia, and industry will advance the global society," Warren said. To help acknowledge the great philanthropic spirit of the group before him in collectively working toward this goal, Warren then introduced Andrew Baker, a Materials \& Process Engineer at Boeing Research
\& Technology and one of the 2019 Structural Materials Division Young Leaders Professional Development Award recipients. Baker shared his story with the crowd, noting the role the Foundation has played along the way. As a student, he received a travel grant to attend a TMS meeting, where he became more involved in the Society. Later he attended the Emerging Leaders Alliance conference through the support of the Foundation. And today, Baker is not just a TMS member and current Young Leader, but an active volunteer, using his expertise to serve the Society as a member of several technical and functional committees.

The evening concluded with Warren and Baker presenting 2018 TMS Foundation Lifetime Giving Honorific Society inductees with their society pins, and one more note of thanks. "You have distinguished yourselves as scientists, mentors, leaders, and philanthropists. Thank you for your ongoing commitment and generosity to the TMS Foundation," Warren said. The inductees, pictured below, are: (front row, from left) Kevin and Maria Oliva Hemker (Titanium Society); Jeffery Gibeling (Silver Society); William Harrigan (Silver Society); Jean and Bill Nix (Silver Society); Wendelin Wright (Silver Society); Timothy Wiehs (Silver Society); Bonnie and David Shifler (Titanium Society); Dan Miracle (Titanium Society); Deepankar Pal (Titanium Society); (back row, from left) Carl Cady (Gold Society); Cheryl and Warren Oliver (Titanium Society); Vivien and Jim Earthman (Silver Society); Cecilia and Michael Mills (Silver Society); Marilyn and George Pharr (Titanium Society); and Marc Meyers (Gold Society).

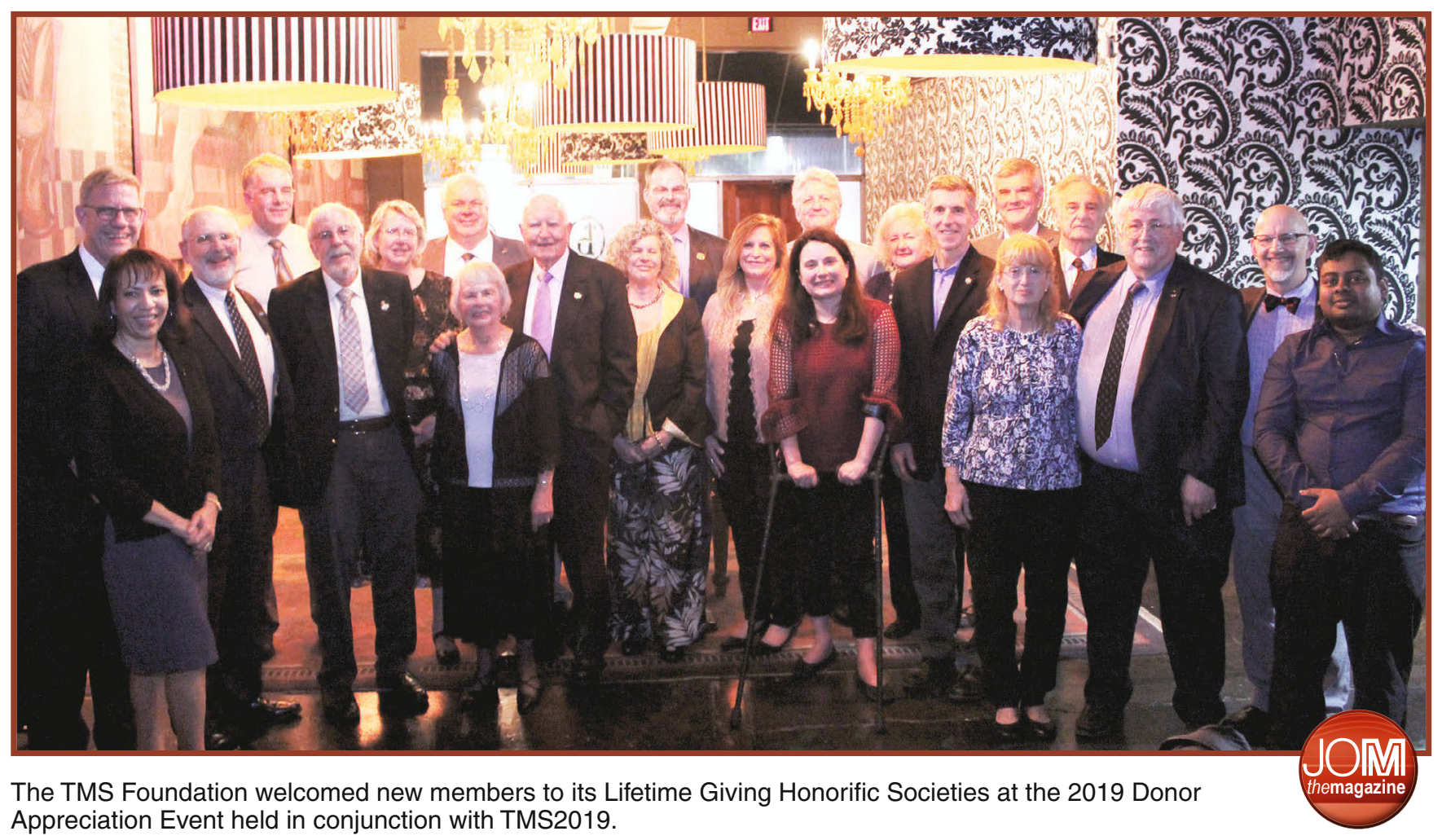

Appreciation Event held in conjunction with TMS2019. 